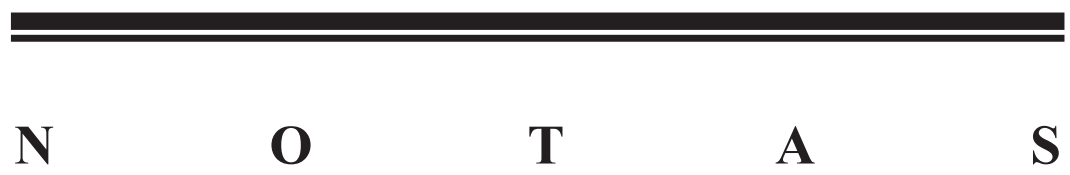




\section{SEIS ACOTACIONES PRELIMINARES PARA UNA TEORÍA DE LA VALIDEZ JURIDICA}

Manuel Atienza y Juan Ruiz Manero

Universidad de Alicante

\section{Validez y normas constitutivas}

$$
65 \begin{aligned}
& \text { os actos contrarios a las normas imperativas y a } \\
& \text { las prohibitivas -reza el art. } 6.3 \text { del Código civil } \\
& \text { español- son nulos de pleno derecho". El acto de } \\
& \text { matar a otra persona, sin que medie una causa de } \\
& \text { justificación, es indudablemente contrario a una nor- }
\end{aligned}
$$
ma imperativa (si formulamos la norma correspondiente como "obligatorio abstenerse de matar") o prohibitiva (si la formulamos como "prohibido matar"). Sin embargo, produciríamos estupor en cualquier interlocutor si calificásemos el acto de una persona $\mathrm{A}$, consistente en dar muerte a otra persona B, como "nulo de pleno derecho". Y es que predicados como "nulo de pleno derecho", y, en general, los derivados de las nociones de validez y nulidad, sólo operan con sentido para calificar acciones (y resultados de acciones) institucionales, entendiendo por tales, de acuerdo con la ya clásica caracterización de Searle ${ }^{1}$, aquellas que no son posibles en ausencia de reglas constitutivas, esto es, de reglas que crean la posibilidad de dichas acciones y resultados, acciones y resultados cuyo concepto es lógicamente dependiente de la regla en cuestión. Tal es lo que ocurre con acciones y resultados no como matar y estar muerto (posibles en ausencia de regla alguna y cuyo concepto no depende de ninguna regla) sino con acciones tales como celebrar un contrato, aprobar una ley o dictar una sentencia y con sus correspondientes resultados (contrato, ley o sentencia). Aquí la predicación de validez o nulidad tiene pleno sentido tanto en relación con las acciones (celebración válida de un contrato, aprobación válida de una ley, etc.) como con sus correspondientes resultados (contrato válido, ley válida, etc.).

\footnotetext{
${ }^{1}$ Searle $(1969,1995)$.
} 
El que el universo de predicación de validez o nulidad está constituido por acciones y resultados institucionales, en el sentido indicado, es algo que los juristas han intuido tradicionalmente lo suficiente como para usar estos predicados en los contextos apropiados, pero no es algo de lo que, en general, hayan conseguido dar cuenta de una forma articulada que resulte teóricamente satisfactoria. Así, por ejemplo, los civilistas usan la expresión "actos jurídicos" para cubrir acciones institucionales, de las que tiene pleno sentido predicar validez o nulidad, tales como la reclamación de una deuda, la celebración de un matrimonio o de un contrato. Pues bien: un civilista de la talla de Carlos Lasarte define los "actos jurídicos" simplemente como "las conductas o actuaciones humanas, realizadas de forma consciente y voluntaria, a las que el ordenamiento jurídico atribuye cualquier tipo de efectos o consecuencias" ${ }^{\prime 2}$, en la misma línea, verdaderos maestros del Derecho civil español contemporáneo tales como Luis Díez-Picazo y Antonio Gullón enfatizan que los actos jurídicos son tales, y no meros hechos, simplemente "porque derivan de una actuación (declaración, conducta) humana realizada con conciencia y voluntad"3. Características estas -conciencia y voluntariedad, atribución por el Derecho de consecuencias jurídicas- que el asesinato o las calumnias, por ejemplo, reúnen perfectamente. Si los juristas han evitado hablar de asesinatos o calumnias válidos o nulos es, pues, por sus intuiciones certeras y no por su aparato conceptual explícito, lastrado por la carencia del concepto de regla o norma constitutiva.

El término "validez" (o "válido", "inválido", etc.) parece funcionar como un término de enlace en el siguiente sentido: a veces decimos que determinados resultados (como un contrato, una sentencia, una ley, un acto administrativo...) son válidos o inválidos, apuntando con ello a que de tales resultados se derivan determinadas consecuencias o efectos jurídicos. Y otras veces la predicación de validez apunta a las condiciones o antecedentes de esos resultados (y decimos así que tal testamento es válido porque ha sido otorgado de acuerdo con los requisitos establecidos para ello en el Código civil o que tal contrato es inválido porque uno de los contratantes era menor de edad al momento de la celebración). Quiere ello decir que, a propósito de la validez, podemos referirnos tanto a sus antecedentes o condiciones (o a su negación: a los vicios de la validez) como a sus consecuencias: a cuáles son los efectos de que un cierto resultado institucional sea válido o inválido (o válido o inválido en diversos grados).

\footnotetext{
${ }^{2}$ Lasarte (1992), p. 432.

${ }^{3}$ Díez-Picazo y Gullón (1994), p. 482.
} 
De acuerdo con la tipología de las normas que elaboramos en Las Piezas del Derecho ${ }^{4}$, las normas que establecen las condiciones o antecedentes para la producción o el surgimiento de resultados institucionales deben entenderse como normas constitutivas (categoría que se contrapone a la de las normas regulativas, esto es, a las que estipulan obligaciones, prohibiciones o permisos). Las normas constitutivas presentan una estructura condicional que puede reducirse al siguiente esquema general: si se dan determinadas circunstancias, entonces se produce el resultado institucional R. Este esquema general es, como puede verse sin dificultad, estrictamente equivalente al de Searle: X cuenta como Y en las circunstancias C. Ahora bien: en el caso de los sistemas normativos complejos, tales como el Derecho, es esencial distinguir entre dos tipos de normas constitutivas, según que en el antecedente figure o no una acción (o una serie de acciones: un procedimiento) que ha de realizar un determinado sujeto (o sujetos) para producir el resultado. De manera que hemos de distinguir entre dos tipos de normas constitutivas. El primer tipo está integrado por aquéllas que establecen meramente que si se da un cierto estado de cosas $\mathrm{X}$, entonces se produce un cierto resultado institucional R. Denominamos a las normas de este tipo normas puramente constitutivas. El segundo tipo está integrado por aquellas normas cuyo antecedente contiene un elemento ulterior: una acción o procedimiento. De manera que el esquema de estas normas sería el siguiente: si se da el estado de cosas $\mathrm{X}$ y un sujeto (o sujetos) $\mathrm{Z}$ realiza la acción (o serie de acciones: procedimiento) $\mathrm{Y}$ entonces se produce el resultado institucional R. Las normas de este tipo son las normas que confieren poderes normativos.

Por otro lado, el resultado institucional (R), tanto de las normas puramente constitutivas como de las normas que confieren poderes puede ser un cambio normativo de alcance ilimitado (o potencialmente ilimitado) respecto de los destinatarios y las acciones o un cambio limitado a acciones o individuos determinados. De esta forma, si combinamos la distinción entre normas puramente constitutivas y normas que confieren poder con el carácter ilimitado o limitado de los cambios normativos introducidos por los resultados obtenemos los siguientes cuatro tipos de normas:

1) Normas que confieren poder cuyo resultado es un cambio normativo de alcance ilimitado: leyes, reglamentos, etc.

2) Normas que confieren poder cuyo resultado es un cambio normativo de alcance limitado: contratos, fallos judiciales, resoluciones administrati$\operatorname{vas}^{5} \ldots$

\footnotetext{
${ }^{4}$ Atienza y Ruiz Manero (1996).

${ }^{5}$ Naturalmente, en los tanto en los ejemplos contenidos aquí, como en los referidos a normas que confieren poder cuyo resultado es un cambio normativo de alcance ilimitado, nos
} 
3) Normas puramente constitutivas, cuyo resultado es un cambio normativo de alcance ilimitado: costumbres...

4) Normas puramente constitutivas cuyo resultado es un cambio normativo de alcance limitado: alcanzar la mayoría de edad, adquirir la condición de heredero...

Esta pluralidad de tipos de normas a partir de las cuales predicamos validez o nulidad explica la variedad de contextos en los que llevamos a cabo predicaciones de validez: hablamos, así, de contratos, leyes o sentencias válidas - por referirnos a los casos más centrales-, pero también de convocatorias, votaciones o reclamaciones válidas, de costumbres válidas, de adquisición válida de una servidumbre por prescripción... Un esquema ordenado de aquello que puede ser calificado como válido o inválido sería el siguiente:

1) los resultados institucionales que entrañan la promulgación o derogación de normas generales y abstractas de origen deliberado: leyes, reglamentos....

2) los resultados institucionales que entrañan cambios en la situación normativa de individuos determinados respecto de clases de acciones o de acciones determinadas producidos por actos normativos de las autoridades (sentencias judiciales, resoluciones administrativas) o de los particulares (negocios jurídicos).

3) las resultados institucionales que entrañan el surgimiento o la extinción de normas generales y abstractas de origen espontáneo: costumbres...

4) los resultados institucionales que entrañan cambios en la situación normativa de individuos determinados respecto de clases de acciones o de acciones determinadas producidos por la mera ocurrencia de ciertos hechos: adquirir una servidumbre por prescripción, alcanzar la condición de heredero...

Pero este listado es incompleto, como advertimos en cuanto atendemos a que las normas que confieren poderes establecen, a diferencia de las normas puramente constitutivas, una acción o una serie de acciones (un procedimiento) como condición para la producción del resultado institucional y a que la realización de cada una de estas acciones implica la producción de un resultado institucional digamos intermedio: por ejemplo, la acción de convocar válidamente el Pleno del Congreso por parte de su Presidente para debatir y votar un cierto proyecto de ley implica que dicho Pleno ha que-

referimos a los casos centrales de los resultados institucionales a los que hacemos referencia. Esto es, dejamos de lado tanto, por ejemplo, las llamadas leyes singulares -esto es, aquellas leyes que no contienen normas generales y abstractas, sino meras respuestas a casos individuales-, por una parte, como, por otra, las llamadas sentencias interpretativas (esto es, aquellas sentencias que establecen la interpretación admisible de normas generales y abstractas). 
dado válidamente convocado a tales efectos. Obtenemos de aquí un nuevo integrante del universo de predicación de validez o invalidez:

5) Las acciones institucionales que forman parte del procedimiento: consentir, convocar, votar... y sus correspondientes resultados: consentimiento, convocatoria, votación....

El análisis de los dos tipos de normas constitutivas que esbozamos en Las piezas del Derecho constituye, pues, nuestro punto de partida para analizar la problemática de la validez ${ }^{6}$. Pero este análisis necesita, creemos, ser afinado, básicamente en el sentido de mostrar cómo deben ser interpretados los diferentes elementos que distinguíamos en estos dos tipos de normas. Veámoslo mediante un ejemplo: el de las normas que confieren poder para establecer normas generales de origen deliberado; en particular, normas legislativas. El esquema de este tipo de normas, como acabamos de recordar, es el siguiente: si se da el estado de cosas $\mathrm{X}$ y un sujeto o sujetos $\mathrm{Z}$ realizan la acción (o serie de acciones) Y, entonces se produce el resultado institucional R (en este caso, una ley válida). Pues bien: el estado de cosas $\mathrm{X}$ comprendería, en el caso de la norma que confiere poder para la producción legislativa, los diversos ámbitos de competencia (ámbitos de validez) de la norma a producir, de la ley: material, personal (los destinatarios), temporal y espacial. La serie de acciones Y equivale al procedimiento complejo de dictar una ley: la serie de actos que tienen lugar, por ejemplo, desde la presentación del proyecto de ley hasta su publicación. Los sujetos Z serían la serie de órganos a los que corresponde efectuar cada uno de la serie de actos que integran ese procedimiento complejo: por ejemplo, el Gobierno en el caso de la presentación del proyecto de ley, la mesa, o el presidente de la cámara, a la hora de convocar una sesión, etc.

El problema que surge con el anterior esquema es que en el mismo no parece haber lugar para el contenido proposicional expresado en el texto de la ley. Y es el caso, sin embargo, que, por ejemplo, las reglas constitucionales que confieren el poder de legislar imponen límites al contenido admisible de las leyes. Así, por ejemplo, el legislador orgánico puede, de acuerdo con ellas, legislar en materia de derechos fundamentales, pero, al hacerlo, debe respetar el "contenido esencial" de los mismos. Desde luego, alguien podría decir que cualquier cuestión de "contenido" puede, en un sentido, reconducirse a una cuestión de "materia" y decir, por ejemplo, que el legislador orgánico puede legislar respecto de toda la "materia" "derechos

${ }^{6}$ La vinculación de la teoría de la validez con la teoría de las fuentes es, pues, obvia. Aguiló (2000), usando el esquema de la distinción entre normas que confieren poder y normas puramente constitutivas, conectó brillantemente esta distinción con la que suele trazarse entre fuentes-acto (cuyo ejemplo paradigmático es la legislación) y fuentes-hecho (cuyo ejemplo paradigmático es la costumbre). 
fundamentales", pero que no puede hacerlo respecto de la "materia" "contenido esencial" de los mismos. Pero esta sería una forma de hablar cuanto menos confusa, ya que el legislador orgánico sí puede legislar en materia de contenido esencial de los derechos fundamentales (sin ir más lejos, para establecer medidas de protección o de tutela de dicho contenido esencial). Parece bastante más claro decir que el legislador lo que no puede es dictar una norma, en materia de derechos fundamentales, cuyo contenido vulnere el "contenido esencial" de tales derechos. Parece, pues, conveniente, reservar el término "materia" para hacer referencia a aquello (a aquella porción del mundo) sobre la que se legisla y "contenido" para hacer referencia al significado del texto mediante el que se legisla. De otro lado, parece claro que cuál sea la "materia" sobre la que decimos que versa una norma es cuestión que depende de cuál sea la ordenación del mundo de la que partamos y que una misma norma puede verse, según la perspectiva desde la que dividamos el mundo, como reguladora de materias diferentes: por ejemplo, de una ley que ordene la adopción de un mecanismo "de cremallera" entre personas de diferente sexo a la hora de confeccionar candidaturas electorales, podríamos entender, sin que ninguna de las dos posibilidades tenga mejor título que la otra, bien que su materia es el régimen electoral o bien que lo es la promoción de la mujer. Pero, en todo caso, parece claro que una cosa es acerca de qué (de qué porción del mundo, lo que dependerá de la perspectiva adoptada) versa una norma y otra cosa es la manera, el cómo (con qué contenido proposicional), esa norma regula esa porción del mundo. Parece, pues, que a nuestro esquema inicial debe añadirse al elemento $X$ (estado de cosas, en el que incluimos la materia), al elemento $Z$ (sujeto o sujetos), y al elemento $\mathrm{Y}$ (acción o procedimiento) un nuevo elemento $\mathrm{C}$, con el que aludiríamos al contenido (o a los límites de contenido). De manera que el esquema vendría a ser, finalmente, el siguiente: si se da el estado de cosas $\mathrm{X}$ y los sujetos $\mathrm{Z}$ realizan la serie de acciones (el procedimiento) $\mathrm{Y}$ dando lugar a un contenido $\mathrm{C}$, entonces se produce el resultado institucional $\mathrm{R}$ (esto es, en el caso que nos ocupa, una ley válida).

\section{Normas constitutivas y proposiciones anankásticas. Los límites de la analogía y la peculiaridad del mundo institucional}

En Las piezas del Derecho explicamos las normas constitutivas como el análogo, en el mundo institucional, de lo que son las proposiciones anankásticas respecto del mundo natural. En relación con el mundo natural, las proposiciones anankásticas dan cuenta de que la ocurrencia de ciertos hechos es condición necesaria y/o suficiente de la ocurrencia de otros ciertos hechos: por ejemplo, que, en condiciones normales de presión, el que el agua alcance $100^{\circ} \mathrm{C}$ de temperatura, es condición necesaria y suficiente para que el 
agua entre en ebullición. Análogamente, las normas constitutivas establecen, respecto del mundo institucional, que la ocurrencia de ciertos hechos, junto con (eventualmente: en el caso de las reglas que confieren poderes) la realización de ciertas acciones, es condición necesaria y/o suficiente de la producción de ciertos resultados institucionales o cambios normativos.

Esta analogía es, a nuestro juicio, fecunda, porque permite ver cómo unas y otras -proposiciones anankásticas y normas jurídicas constitutivas, especialmente normas que confieren poderes- son usadas por los sujetos interesados en ellas: bajo la forma de reglas técnico-naturales, en el primer caso (que indican cómo producir determinados resultados naturales o cambios en el mundo natural) y bajo la forma de reglas técnico-institucionales, en el segundo (qué indican cómo producir determinados resultados institucionales o cambios normativos). Pero el acento debe desplazarse ahora, más bien, hacia la consideración de los límites de la analogía. Y estos límites son básicamente tres, que corresponden, o derivan, de otras tantas peculiaridades de la realidad jurídico-institucional -constituida para servir a ciertos propósitos mediante las reglas constitutivas- frente a la realidad natural - descrita mediante las proposiciones anankásticas. La primera es la posibilidad de lo que podríamos llamar el éxito tramposo, posibilidad ausente en el mundo natural. Si, en circunstancias normales, el agua no alcanza los $100^{\circ} \mathrm{C}$, sencillamente no entrará en ebullición. Análogamente, podríamos decir que un documento no es un testamento ológrafo a menos que haya sido escrito de puño y letra por el testador (a quien llamaremos A) y no, digamos, por una tercera persona (B) que suplanta su personalidad. Pero supongamos que B lo hace de forma tan perfecta que, una vez fallecido A, el manuscrito falsificado por B cuente de forma no controvertida como el testamento de A. Y el "contar como" es la medida del éxito en el mundo institucional. La segunda característica importante es que los cuatro elementos que hemos distinguido en el antecedente del esquema de las normas que confieren poder ( $\mathrm{X}$ o estado de cosas, $\mathrm{Z}$ o sujeto u órgano, Y o acción-procedimiento, $\mathrm{C}$ o contenido) pueden estar, a su vez, regulados por normas regulativas, que establecen obligaciones, prohibiciones o permisos, lo que no ocurre en el ámbito de la realidad natural ( $s i$ se parte, se entiende, de una concepción no animista de la misma). Por ejemplo, el Gobierno sólo puede emitir decretos-leyes si es un componente del estado de cosas $\mathrm{X}$ el que las materias que pretende regular mediante este instrumento se encuentran en una situación "de extraordinaria y urgente necesidad" de intervención normativa, estándole prohibido en los demás casos. La tercera característica - que viene a confluir con las dos anteriores- es que, si se trata de sistemas institucionalizados como el Derecho, el que algo sea dejado de lado como un resultado normativo meramente aparente (nulo, en un cierto sentido que se precisará seguidamente), o reco- 
nocido como un resultado genuino, o, dentro de los resultados genuinos, el que sea visto como un resultado plenamente válido (regular) o como afectado de algún tipo de irregularidad (en relación con lo cual el Derecho prevé diferentes consecuencias según la entidad de dicha irregularidad) depende del pronunciamiento autoritativo de ciertos órganos. Dichos órganos deben, de acuerdo con el Derecho, realizar dichos pronunciamientos atendiendo, desde luego, a que se hayan cumplido las diversas condiciones que el Derecho establece como requisitos de la producción válida del resultado de que se trate, pero dichos pronunciamientos son vinculantes (y, si se trata de órganos de última instancia, definitivamente vinculantes) aun cuando, desde dicha perspectiva, sean equivocados o incorrectos.

¿Cuáles son los requisitos mínimos para que un acto que presente cierta apariencia de ser un caso de uso de una regla que confiere poder produzca ciertos efectos jurídicos, al menos el efecto mínimo de necesitar ser anulado por un órgano investido de autoridad para no producir los efectos que pretende? En un trabajo reciente, Bruno Celano ha sostenido que este problema marca los límites del normativismo como enfoque: que en este punto "el paradigma nomodinámico debe ceder el paso a, o de algún modo conjugarse con, un paradigma teórico distinto: el paradigma convencionalista" $\mathrm{Y}$ es que, en efecto, resulta inútil buscar en el sistema jurídico mismo ${ }^{8}$ una respuesta a esta cuestión. El que un acto cuente como jurídico en el sentido mínimo de requerir un pronunciamiento de un órgano para dejar de contar como tal depende de creencias, prácticas, etc. que es imposible reconstruir con precisión. Pueden proporcionarse, desde luego, ciertos ejemplos indudables, pero nada más. Parece, por ejemplo, que carecería de cualquier efecto jurídico una "ley" en la que las Cortes españolas "legislaran" sobre la forma de llevar a cabo las ejecuciones en las prisiones del Estado de Florida; o una "sentencia" dictada por un subdelegado del Gobierno; o una "ley" que no hubiese sido dictada por las Cortes, sino por una Asamblea de Amnistía Internacional.

En los ejemplos anteriores, se trata de productos que, ni siquiera prima facie, aparecen como instancias de aquello que pretenden ser (esto es, de leyes o de sentencias españolas). Pero podemos imaginar muchos otros en los que prima facie sí se da esta apariencia y respecto de los cuales, para que no cuenten como aquello que pretenden ser, es preciso un pronunciamiento de un órgano de control investido de autoridad. Pensemos, por volver a un ejemplo propuesto páginas atrás, en el caso del testamento

\footnotetext{
${ }^{7}$ Celano (2001) ,p. 424.

${ }^{8}$ Véase, más adelante, la distinción entre el Derecho como sistema y el Derecho como práctica.
} 
ológrafo hábilmente falsificado: sin un pronunciamiento judicial sobre su falsedad, contaría como aquello que pretende ser. $\mathrm{O}$ pensemos en un texto, promulgado como ley, que no hubiera obtenido en el parlamento la mayoría requerida. En todos estos supuestos, el órgano de control debería rechazar tales productos como los resultados institucionales que pretenden ser: debería considerarlos constitutivamente inválidos o, si se prefiere, jurídicamente inexistentes. Pero su intervención sería necesaria para que no desplegaran sus efectos, a diferencia de lo que ocurriría con los ejemplos extravagantes (la "ley" española sobre las ejecuciones en Florida, la "sentencia" del subdelegado del gobierno, etc.) que poníamos hace un momento. La existencia o validez constitutiva es lo que suele llamarse un concepto clasificatorio, esto es, un concepto que posibilita meramente la adscripción a una clase: ello no excluye, naturalmente, la posibilidad de casos dudosos o controvertibles, pero algo que se presenta como una instancia, un caso individual, de un cierto resultado institucional genérico (como testamento o ley) o es considerado o no es considerado ( $\sin$ que quepa tercera posibilidad o gradualidad alguna), como tal instancia del correspondiente resultado institucional. De las cuestiones de existencia o validez constitutiva deben distinguirse las cuestiones de regularidad o validez regulativa. El planteamiento de estas cuestiones presupone la existencia o validez constitutiva del resultado institucional de que se trate, esto es, que ese resultado institucional debe ser considerado como una instancia de aquello de lo que pretende constituir una instancia: por seguir con los ejemplos, de testamento o de ley. De lo que se trata es de si un resultado institucional existente como tal contiene defectos, respecto del sujeto u órgano, de la materia, del procedimiento o del contenido, por haber violado alguna norma regulativa referida a alguno de estos cuatro elementos. La regularidad o validez regulativa es, a diferencia de la existencia, un concepto no meramente clasificatorio sino comparativo: no se aplica mediante un mero par válido/inválido, sino mediante una escala gradual que abarca desde la validez plena en un extremo a la nulidad de pleno Derecho en el otro (en el caso de vicios de validez extremadamente graves), pasando, según la entidad de los mismos, por la anulabilidad y (al menos en el ámbito del Derecho público) los llamados vicios no invalidantes.

Algunos ejemplos de vicios de validez (regulativa) serían los siguientes. Por lo que hace a la materia (y el mismo ejemplo serviría, visto desde otro ángulo, para el órgano) pensemos en una ley estatal que invade competencias exclusivas de una comunidad autónoma ${ }^{9}$, o, por lo que hace al procedimiento, que ha sido aprobada sin admitir a trámite las enmiendas de un

\footnotetext{
${ }^{9}$ Alguien podría decir que las Cortes españolas son tan incompetentes para legislar sobre materias de Florida como sobre materias reservadas a la exclusiva competencia de una Comu-
} 
cierto grupo parlamentario que, de acuerdo con el reglamento de la cámara, hubieran debido admitirse a trámite. Y, por lo que hace al contenido, repárese en el siguiente ejemplo, que nos servirá también para mostrar los límites de los mecanismos de control de la regularidad: ¿qué ocurriría con una ley dictada por las Cortes, de acuerdo con el procedimiento constitucionalmente establecido, que supusiera una violación flagrante de la Constitución: que estableciera, por ejemplo, la pena de muerte, en tiempos de paz, para los delitos de terrorismo? De entrada, cabe decir, con entera razón, que esta ley debería ser anulada por el Tribunal Constitucional. Pero supongamos que el Tribunal Constitucional actúa de forma contraria a sus deberes y declara esta ley conforme con la Constitución. De acuerdo con el antecedente de la regla que confiere poder para legislar y de acuerdo con el antecedente que confiere al Tribunal Constitucional poder para decidir sobre la constitucionalidad de las leyes, tal ley y tal sentencia serían irregulares (esto es, regulativamente inválidas). Pero el resultado institucional de ambas resultaría inatacable mediante procedimientos jurídicos. $\mathrm{Y}$ el juez al que correspondiera enjuiciar un caso en el que la ley resultara aplicable se encontraría en la disyuntiva de o bien ser fiel a la Constitución, en cuanto que proscribe la pena de muerte, o bien ser fiel también a la Constitución, pero en cuanto que ordena la obediencia a las autoridades instituidas por ella misma, y, en especial, la vinculación de los tribunales ordinarios a la interpretación de la Constitución llevada a cabo por el Tribunal Constitucional. El sistema jurídico mostraría, en este caso, contener una tensión irresuelta respecto de los criterios últimos de validez jurídica. Y la posibilidad de una tensión de este género no puede quedar nunca excluida en un sistema cuyas normas supremas tengan un contenido distinto del puro conferimiento de poderes, y reclamen obediencia para ellas mismas y también para las autoridades que ellas mismas instituyen.

\section{La distinción entre validez constitutiva y validez regulativa sólo tiene sentido en el contexto de sistemas desarrollados}

En órdenes normativos prejurídicos, o en formas embrionarias de sistema jurídico, los juicios de validez, o bien no tienen sentido, o bien revisten una menor complejidad. Lo primero es seguramente lo que ocurriría con un sistema (si es que en tales condiciones puede hablarse de 'sistema') integrado solamente por normas consuetudinarias de conducta (un régimen

nidad Autónoma. En cierto sentido ello es, desde luego, así. Pero no debe olvidarse que, de acuerdo con el Derecho, así como en el primer caso fracasaría en su empeño, en el segundo conseguiría los efectos que pretende conseguir, salvo que la ley fuera anulada por el Tribunal Constitucional. 
exclusivo de normas primarias en el sentido de Hart). No podría hablarse de normas jurídicas como algo diferente de las normas sociales en general y no parece que pudiera hablarse ni de validez como existencia institucional, ni de validez como regularidad. La validez como existencia institucional presupone alguna diferencia con la mera existencia social; pero semejante contraste entre existencia social y existencia institucional no puede darse en un régimen de este tipo. Tampoco, a mayor abundamiento, puede hablarse de validez como regularidad: las normas regulativas que se usan para llevar a cabo el juicio de validez no son meras normas de conducta, sino que presuponen la posibilidad de constituir resultados institucionales diferenciados de las meras existencias sociales. Si un sistema normativo (en el caso de que realmente pudiera hablarse de 'sistema' en tales casos) no contiene esa doble articulación, entre normas primarias de conducta y normas secundarias que constituyen la posibilidad de la producción (o del surgimiento) de resultados institucionales, por un lado, y que operan como parámetros desde los que juzgar la regularidad de los mismos, no se plantean problemas de validez.

Más interesante es el supuesto constituido por algo que es ya indiscutiblemente un sistema jurídico (aunque no desarrollado): un sistema integrado exclusivamente, en su vertiente regulativa, por normas consuetudinarias, pero en el que hubiera jueces encargados de resolver autoritativamente las disputas usando esas normas consuetudinarias como fundamento de sus resoluciones. Este sistema sí que contaría con una doble articulación aunque, si se quiere, empobrecida por el hecho de que no hay en él normas secundarias que posibiliten el cambio deliberado. Pero hay en él normas de adjudicación y una regla de reconocimiento (por más que tuviese un carácter bastante rudimentario). En él contarían como normas válidas para la resolución autoritativa de las disputas todas las normas consuetudinariamente establecidas. Quiere ello decir que, respecto de las normas, en este sistema no cabría la distinción entre validez como existencia y validez como regularidad (aquí, validez y existencia significan lo mismo): ninguna costumbre puede ser regulativamente válida o inválida, porque el sistema carece de parámetros regulativos de validez. Las decisiones de los jueces, en cambio, sí serían susceptibles de análisis en términos de la distinción anterior: pues una cosa es que algo cuente como decisión judicial (que sea constitutivamente válido como tal) y otra que sea una decisión correcta de acuerdo con el sistema (regulativamente válida): las normas consuetudinarias -junto con las normas que confieren a un cierto sujeto el poder de actuar como juez- proporcionan aquí los parámetros de corrección o validez regulativa. 


\section{Juicios de validez y regla de reconocimiento}

Los juicios de validez, tanto constitutiva como regulativa, se refieren, en última instancia, a la regla de reconocimiento del sistema de que se trate. Esta noción de 'regla de reconocimiento' debe entenderse, a nuestro juicio, con las tres siguientes precisiones. En primer lugar, que los criterios últimos de validez jurídica contenidos en la regla de reconocimiento no tienen por qué ser exclusivamente criterios autoritativos o de pedigrí, sino que -como ya indicara Carrió ${ }^{10}$ hace más de tres décadas y aceptara el propio Hart en el postcriptum a The Concept of Law ${ }^{11}$ - la regla de reconocimiento puede integrar asimismo criterios de naturaleza sustantiva y, en particular, criterios morales. Esta tesis es, como se sabe, el eje vertebrador de la nueva e influyente modalidad de positivismo jurídico que se conoce con el nombre de 'positivismo incluyente'. En segundo lugar, que las cadenas de validez no se limitan a los procedimientos de delegación, sino que vienen determinadas también por relaciones de deducibilidad y de coherencia. Y, en tercer lugar, que la validez debe distinguirse de la pertenencia al sistema jurídico y de la obligatoriedad (o permisividad) de utilizar determinados enunciados (determinados materiales) en la práctica justificativa. Los tres conceptos (los tres juicios: de validez, de pertenencia al sistema y de obligatoriedad o permisividad) dependen del de regla de reconocimiento, pero de manera distinta. A su vez, la distinción anterior presupone la que puede trazarse entre el Derecho considerado como sistema o como práctica (o conjunto de prácticas).

El sistema jurídico es un conjunto de enunciados de carácter normativo y no normativo (como es el caso de las definiciones legales) cuyos integrantes reúnen ciertos requisitos: 1) Se trata de enunciados normativos y no normativos bien independientes -aquellos a los que remite directamente una determinada regla de reconocimiento-, bien derivados de los anteriores mediante procedimientos autoritativos -esto es, mediante el uso de reglas que confieren poderes de producción normativa- o mediante criterios de inferencia lógica o de coherencia axiológica; 2) tienen cierto carácter "productivo", esto es, pueden ser utilizados en un número potencialmente ilimitado de ocasiones: por ejemplo, tal norma del Código Civil, o de la Constitución, contribuye a fundamentar un número potencialmente ilimitado de actos pertenecientes a la práctica justificativa, de la misma manera que una regla gramatical contribuye a producir un número potencialmente ilimitado de actos gramaticalmente correctos (de actos consistentes en aplicar el código

\footnotetext{
${ }^{10}$ Carrió (1970 -en 1986, IV- y 1981).

${ }^{11}$ Hart (1994).
} 
de la lengua) o una regla lógica, un número potencialmente ilimitado de argumentos (lógicamente válidos).

Ahora bien, además de como un sistema, el Derecho puede concebirse también como una práctica social compleja: la práctica jurídica que consiste en decidir casos y en justificar esas decisiones, en producir nuevas normas, en asesorar a alguien sobre cómo hacer para producir tal cambio normativo, etc. La práctica rebasa, naturalmente, al sistema, de la misma manera que ocurre con el habla respecto de la lengua, o con la práctica de la argumentación respecto a las reglas de la lógica. Así, la práctica de la justificación judicial utiliza -en cuanto ingredientes necesarios de la misma, en cuanto fundamentos justificativos- elementos como puede ser un determinado contrato, una norma de otro sistema jurídico o una generalización empírica proveniente de una determinada ciencia o conocimiento no científico que, naturalmente, no forman parte del sistema jurídico de referencia.

Pues bien, la validez no es lo mismo que la pertenencia al sistema, puesto que, como hemos visto, los resultados institucionales de alcance limitado (como un contrato o la adquisición de una servidumbre) suelen ser calificados como válidos o inválidos, pero no pertenecen al sistema (por la restricción que implica el requisito 2). No todo lo que calificamos de válido pertenece al sistema, pues esto último supone el requisito adicional del alcance potencialmente ilimitado. Y no todos los enunciados que deben (o pueden) ser usados en una práctica justificativa como premisa de fundamentación son enunciados válidos (porque no son necesariamente el consecuente de una norma constitutiva ni derivan del mismo por razones de inferencia deductiva o de coherencia) ni enunciados pertenecientes al sistema. Podríamos decir que los enunciados válidos son un subconjunto de los enunciados que se debe (o se puede) utilizar como fundamentación y que los enunciados pertenecientes al sistema son un subconjunto de los enunciados válidos.

\section{Nulidad y sanción}

Una teoría de la validez consiste básicamente (por su carácter, al que antes nos hemos referido repetidamente, de término de enlace) en una teoría de los requisitos de la validez (y de su opuesto: de los vicios de validez) y en una teoría de las consecuencias de la validez (y de su opuesto: de las consecuencias de sus vicios: una teoría de la nulidad). Las clasificaciones que se hacen de tipos de vicios (por ejemplo, la de Guastini ${ }^{12}$ ) vienen a coincidir con cada uno de los elementos distinguidos en el antecedente: por ejemplo, vicios materiales (en $X)$, vicios de competencia $(Z)$, vicios procedimentales

\footnotetext{
${ }^{12}$ Guastini (1993), pp. 51 ss. , (1995), pp. 146 ss.; (1999), pp.331 ss.
} 
(Y) y vicios de contenido ( C). Y, por su lado, la entidad de los vicios de validez determina consecuencias de mayor o menor gravedad: desde la nulidad radical o de pleno Derecho a la mera presencia de vicios no invalidantes, pasando por la anulabilidad.

¿Puede verse aquí un paralelismo con lo que, en el campo de las normas regulativas, sería la teoría de los ilícitos y la teoría de la sanción? Las relaciones entre sanción y nulidad constituyen uno de los temas en los que hay mayores discrepancias entre los teóricos del Derecho y los juristas. Los primeros, siguiendo un famoso pasaje de $\mathrm{Hart}^{13}$, suelen negar enfáticamente que la nulidad sea una forma de sanción. La razón aducida por Hart es que las normas que confieren poderes normativos no pretenden disuadir a sus destinatarios de que lleven a cabo actos que no satisfagan en cuanto a su forma las exigencias jurídicas, esto es, que no constituyan actos de uso de una norma que confiere poder. Por ejemplo, la norma que confiere el poder para testar no pretende disuadir a la gente de que mantenga conversaciones informales sobre su voluntad relativa al destino de sus bienes tras su muerte. Sencillamente, no reconoce estas conversaciones informales como testamento. Y la norma que condiciona la producción del resultado institucional "ley" a la obtención de una cierta mayoría no pretende disuadir a los parlamentarios de que voten en contra de los proyectos de ley que se les presenten. Sencillamente, niega la cualidad de ley a los proyectos que no hayan obtenido la mayoría requerida. Pero, como muestran estos ejemplos, en lo que Hart está pensando -y tiene, desde luego, respecto de ello, toda la razón- es en actos que no pretenden ser casos de ejercicio de un poder normativo. Pero la cosa es bien distinta cuando se trata de actos que se presentan al menos prima facie o de entrada como casos de ejercicio de un poder normativo y que al hacerlo así pretenden dar lugar a un resultado institucional, que bien implique un cambio en el universo de las normas generales, bien en la situación normativa de individuos determinados. Cuando se trata de actos con esta pretensión -o, lo que es lo mismo, de actos que superan el umbral más allá del cual es necesario un pronunciamiento autoritativo para su anulación- la nulidad (en sus diversos grados) cumple un papel análogo al de la sanción en relación con las normas regulativas. Si una función central de la sanción es el de prevenir la comisión de conductas indeseables, una función central de la nulidad (en sus diversos grados) es la de prevenir la introducción de resultados indeseables en el Derecho. Y también la nulidad implica, como la sanción, un juicio de reproche: lo reprochado aquí es que no se ha usado correctamente la norma que confiere el poder normativo de que se trate. Naturalmente, este reproche puede verse acompañado o no

\footnotetext{
${ }^{13}$ En el tercer capitulo de The Concept of Law (Hart, 1961).
} 
de otro reproche de naturaleza distinta, esto es, del que se deriva de haber violado una norma regulativa. No se produce este segundo reproche, por ejemplo, cuando un negocio jurídico resulta ser nulo como consecuencia de algún mero defecto de forma y sí se produce (podríamos decir, en su grado máximo) en aquellos supuestos en los que la raíz de la invalidez se halla en la comisión de un ilícito penal como ocurre, por ejemplo, en los casos de sentencias o resoluciones prevaricadoras: en estos últimos casos el mismo acto puede verse -utilizando la norma que confiere poder como esquema de interpretación- como afectado de un grave vicio de validez y -si el esquema de interpretación viene aportado por la correspondiente norma regulativa- como constitutivo de un ilícito penal.

Pero, del mismo modo que, utilizando los términos primario y secundario en el sentido en que indica ordenación temporal de su entrada en juego, en el contexto de las normas regulativas distinguimos entre normas primarias (las que establecen lo que está prohibido, es obligatorio o está permitido hacer o no hacer) y de normas secundarias (las que establecen lo que debe hacerse en el caso de que se haya violado una norma primaria, esto es, se haya cometido un ilícito) también cabría distinguir, en el contexto de la validez, de las normas constitutivas, entre normas primarias (las que establecen las condiciones para la producción de resultados institucionales válidos), y normas secundarias (las que establecen las consecuencias en el caso de que se haya incumplido alguno de los requisitos señalados).

\section{Juicios de validez, interpretativos y de aplicabilidad}

Los juicios de validez son, vistos como orientados hacia el antecedente, juicios de relación entre resultados institucionales y normas. Por ejemplo, afirmar que una ley o un testamento son válidos significa, si se entiende el juicio como orientado hacia el antecedente o implica, si se entiende el juicio como orientado hacia el consecuente, que se ha cumplido con determinados requisitos (o sea, se pone en relación la ley con las normas constitucionales que fijan esos requisitos o el testamento con las normas del Código civil que hacen lo propio) y, en consecuencia, se les reconocen ciertos efectos (por haber cumplido tales requisitos, o haberlos cumplido hasta un cierto grado). Los juicios de validez guardan una estrecha conexión con los juicios interpretativos y con los juicios de aplicabilidad, pero no son lo mismo. Como se acaba de decir, un juicio de validez es un juicio de relación entre resultados institucionales y normas: establece que un resultado institucional (por ejemplo, una norma) es válido porque reúne los requisitos establecidos por las normas referidas a su producción. Un juicio interpretativo, por su parte, señala que un término o enunciado de una norma debe entenderse en tal o cual sentido. Y, finalmente, un juicio de aplicabilidad determina que el 
caso tal cae bajo (resulta subsumible en) el supuesto de hecho de la norma de que se trate.

Tal vez valga la pena ilustrar esta distinciones con un ejemplo: en el famoso caso Kalanke, lo que se planteaba era el problema de si era o no válida una determinada norma de una ley del Estado de Bremen que establecía una discriminación positiva a favor de la mujer para acceder (frente a un varón) a un puesto de tal categoría. El tribunal europeo llegó a la conclusión de que no era válida, porque comparó esa norma (lo que se discutía era una cuestión -un requisito- de contenido) con una dircctiva comunitaria de 1976 y encontró que la norma alemana había infringido el requisito de "igualdad de oportunidades", que el tribunal interpreta en un cierto sentido (como igualdad en el punto de partida, no en el de llegada). En un caso posterior, el caso Marshall, lo que se planteó fue si una norma (también en este caso de un Land alemán) contradecía también aquel artículo de la directriz del 76. El tribunal entendió que no, porque aquí había una circunstancia que hacía que el nuevo caso fuera distinto al caso Kalanke, a saber, que la preferencia que se daba a la mujer frente al varón, para acceder a un puesto de superior categoría, no tenía un carácter mecánico

En ambos caso, el tribunal, para resolver el problema de validez, se planteó problemas interpretativos: cómo había que entender el artículo de la directiva comunitaria y los artículos de las leyes alemanas en discusión. Pero conceptualmente la distinción entre problemas de validez y problemas de interpretación parece estar razonablemente clara. Otro tanto podría decirse respecto a los problemas de validez y de aplicabilidad. Una norma puede ser válida pero no aplicable (el supuesto de hecho que regula no permite que en el mismo se subsuma la situación que se trata de juzgar). Y por supuesto, puede ser aplicable pero no válida (como ocurrió con la norma del Estado de Bremen en el caso Kalanke).

\section{Referencias}

Aguiló (2000): Josep Aguiló : Teoría general de las fuentes del Derecho (y del orden jurídico). Ariel, Barcelona.

Atienza y Ruiz Manero (1996). Manuel Atienza y Juan Ruiz Manero: Las piezas del Derecho. Teoría de los enunciados jurídicos, Ariel, Barcelona.

CARrió (1981): Genaro R. Carrió: Dworkin y el positivismo jurídico, UNAM, México.

CARrió (1986, IV): Genaro R. Carrió: "Principios jurídicos y positivismo jurídico" (1970) en Genaro R. Carrió: Notas sobre Derecho y lenguaje, Abeledo-Perrot, Buenos Aires.

Celano (2001): Bruno Celano: "Justicia procedimental pura y teoría del Derecho", en Doxa, $\mathrm{n}^{\mathrm{O}} 24$. 
Díez Picazo y Gullón (1994): Luis Díez Picazo y Antonio Gullón: Sistema de Derecho civil, vol. I, $8^{\text {a }}$ ed., Tecnos, Madrid.

Guastini (1993): Riccardo Guastini: Le fonti del diritto e l'interpretazione, Giuffrè, Milano.

Guastini (1995): Riccardo Guastini: Il giudice e la legge, Giappichelli, Torino.

Guastini (1996): Riccardo Guastini: Distinguendo. Studi di teoria e metateoria del diritto, Giappichelli, Torino.

Hart (1961): Herbert L. A. Hart: The Concept of Law, Clarendon Press, Oxford.

Hart (1994): Herbert L. A. Hart: "Postcript" a The Concept of Law, $2^{\mathrm{a}}$ ed. A cargo de Penélope A. Bulloch y Joseph Raz, Clarendon Press, Oxford.

Lasarte (1992): Carlos Lasarte Álvarez: Principios de Derecho civil. Tomo 1, Trivium, Madrid.

Searle (1969): John R. Searle: Speech Acts. An Essay in the Philosophy of Language, Cambridge University Press, New York.

Searle (1995): John R. Searle: The Construction of Social Reality, The Free Press, New York. 